\title{
Transgression of the Megapolis in the Context of Anthropocosmism
}

\author{
Maryna Prepotenska \\ Doctor of Philosophical Sciences, National Technical University of Ukraine \\ "Igor Sikorsky Kyiv Polytechnic Institute" \\ (Kyiv, Ukraine) \\ E-mail: gautama05@ukr.net \\ ORCID: 0000-0002-5601-7472
}

Stanislav Lose

$\mathrm{PhD}$, Wroclaw University of Science and Technology

(Wroclaw, Poland)

E-mail: stanislaw.lose@pwr.edu.pl

ORCID: 0000-0002-5004-1439

\begin{abstract}
The paper is focused on the study of the "megapolis" phenomenon in the anthropocosmic aspect. The inquiry concludes that "transgression" appears as a leading intention of Homo Urbanus in organizing its habitat in a megapolis. Transgression can be defined as a desire to go beyond space-time limits to the infinity of the Universe. The following substantive attributes of the transgression are defined: anthropic time ("drop out" from the time, "acceleration" and "slowing down" of the time), anthropic space (threedimensional expansion, sensory attack), and complication of the fractal nature of the city. The article describes the social practices of Homo Urbanus that embody following anthropocosmic intentions: the will to order and unity, comprehended time management, sensory filtration, anthropocosmic thinking. The creativity of Homo Urbanus in the context of consolidated responsibility for the future of the planet is considered to be the main factor of the harmonious development of the megapolis.
\end{abstract}

Keywords: megapolis, transgression, Homo Urbanus, anthropic time, anthropic space, fractal nature, anthropocosmic thinking

Received: March 10, 2018; accepted: April 29, 2018

Philosophy and Cosmology, Volume 21, 2018: 94-106

DOI: $10.29202 /$ phil-cosm/21/10

(C) Prepotenska, Maryna, 2018

(C) Lose, Stanislav, 2018 


\section{Introduction}

Nowadays the destinies of mankind are mostly being formed in megapolises. They appear as bifurcation points in the interaction of political, economic, financial and informational flows. Every big city in a metaphorical sense can be considered as a particular planet that includes the nearby territories in its orbit, and all sorts of other objects through the world network. The study of megapolises appears as a highly relevant in the matter of understanding the mankind's future and choosing the proper cultural and civilization strategies. Megapolis can be considered as a particular technogenic absolute in the context of eschatological myths or as the embodiment of an "earthly paradise" idea. However, in both cases, a large city is usually considered as a purely artificial formation created in the flow of technical innovations and focused on the maximum consumption. We presume that the phenomenon of a megapolis surpasses this interpretation, and in its basic manifestations, the big city reveals more profound anthropocosmic tendencies. Such an assumption leads to the global comprehension of the megapolis phenomenon. It can be interpreted as a natural and prior manifestation of the rational accommodation of a man to planetary life. The Homo Urbanus (an inhabitant of a megapolis) appears as a new type of Homo sapiens, who is able to live among the global civilization challenges providing the creative activity.

\section{Purpose and objectives}

The purpose of the article is to study the phenomenon of a "megapolis" in the anthropocosmic context. The important objective of the paper is the representation of Homo Urbanus as a potential creator of the "eternal" habitat. Other objectives are: to discover the actual attributes of the modern urban lifestyle that prove the Homo Urbanus' intentions to go beyond the limits and to show the substantive manifestations of the transgression in the sense-of-life intentions and social practices of the city-dwellers.

\section{Methodology and literature review}

The most reasonable and relevant method to resolve mentioned problems is the integrative interdisciplinary method. It combines philosophical, sociological and psychological points of view, as well as the holistic and comparative perspectives on the distinction between cosmoconcepts and urbo-concepts. In addition, analyzing the lifestyle of a megapolis-dweller, we take into consideration the philosophical, anthropological and existential approaches. This is necessary for a representation of the transgression as a system-forming principle of interaction within the Human-Megapolis-Space triad in the experience of urban everyday life.

In the definition of anthropocosmism, we refer to its traditional explanation as "a system of views, ideals, according to which man appears to be an organic part of the "cosmos", subordinated to its laws and influencing its evolution" [Kirilenko \& Shevtsov, 2010:12]. The origins of "cosmic" interpretation of cities date back to antiquity when "sacred" and "cosmic" had a similar meaning; symbols and interpretations of Man, God, Universe, "earthly" and "heavenly" were intertwined. The archetypal algorithm of the mutuality of "cosmos" and earthly life was set in the emerald tablet of Hermes Trismegistus "What is below corresponds to what is above; and what is above corresponds with what is below, in order to realize the miracles of a single thing". Cosmogony, anthropological myths, the Pythagorean numerical correspondences of the soul and cosmos, the fundamentals of Hinduism and Tibetans' beliefs, the Taoist canon, mystical esoteric teachings, living ethics - all of them contain ideas for 
the dependence of the human habitat on the Universe composition. Ancient mythology and philosophy affirmed the integrity, balance and the existence of the Universe centre, embodying these ideas in the image of the world tree (axis mundi). The ancient Greek city "polis" ( $\pi$ ó $\lambda \mathrm{l} \varsigma$ ) was constructed and comprehended in accordance to the principles of higher harmony. Its solar architecture, the positioning of its centre (agora) and temples followed the law of the "golden mean" and appeared as a reflection of the cosmic principles of space exploration. In addition, the spiritual sense of the Socrates' call "know thyself" extrapolated to the knowledge of both the earthly world and the cosmos, which was conceived as a living being. Likewise, the ancient interpretation of the city as a reflection of the Universe still exists in the Buddhist culture, according to which the city has to be a geometric symbol as well as the mandala [Toffin, 1982: 109]. The idea of the correspondence of the microcosm and macrocosm is one of the most important in Christianity. This idea highlighted the sacredness of the city affirming the ambivalence of the urbanity. The dichotomy of the fallen, sinful city (Babylon) and the ideal sacred city (Jerusalem) appears as archetypal. The whole history of mankind in the "City of God" by St. Augustine of Hippo is interpreted as the coexistence of two "cities", two lifestyles - in accordance to God's regulations or against those regulations. [Augustine of Hippo, 2000] Industry and urbanization rise, made the empirical interpretations of the city more relevant in comparison with its "cosmic" interpretations. At the same time, the idea of a perfect city became the main topic of utopias. Thousands of thinkers, scientists and visionaries, inspired by Tommaso Campanella's "The City of the Sun", were designing perfect future cities on the principles of the unity with Nature and the Universe. It should be noted that some of the "insane" Utopians' ideas became later useful for highly technically equipped "smart city" projects.

However, the principle "what is above is equal to what is below" was permanently present in humanitarian studies of many scholars, whose writings were targeted to reveal the "cosmoplanetary" essence of Man. The postulates of total unity, beauty and cosmic order were supplemented by the apologists of anthropocosmism with a deep faith in human creative mind and humanism. Nikolay Kholodny pointed out that anthropocentrism and anthropocosmism appear as an alternative position. Anthropocentrism considers a Man being the central point of the Universe, whereas anthropocosmism "aspires to... evenly illuminate the whole cosmos with the light of consciousness, and the person himself is illuminated mainly by reflected rays. This happens because the nature and fate of the Man find their correct explanation only in the light of the knowledge of the cosmos as a whole" [Kholodny, 1982: 187]. Volodymyr Vernadsky wrote that anthropocosmism appears as "a system in which the natural (cosmic) and human tendency of the development of science merge into a single whole" [Vernadsky, 1991]. Konstantin Tsiolkovsky as a representation of the flourishing future of civilization culture and nature postulated the continuity and unity of Life and Cosmos: "The Earth will share with its heavenly colonies the surplus of people... Eventually, we will see an infinite Universe with an infinite number of perfect beings" [Tsiolkovsky, 2013: 25]. Investigating the anthropic approaches in cosmology, Vyacheslav Voitsekhovich summed up that "The Universe as an evolving system represents that both its existence and evolutionary ascent, the complication of forms, systems, structures occurs due to the existence of a Man (actual or potential)" [Voitsekhovich, 2010: 33]. Nowadays the goals of the founders of anthropocosmism become extremely relevant. There are two equally possible scenarios due to the level of development of science and technology: annihilation of the planet and civilization or comfortable planetary life.

Let us turn to the subjective sphere, namely to the live experience of the cosmos and life processes. The existential fear of the "Finite of being" naturally followed by an inner rebellion 
of Man, which manifests itself as the desire of infinite self-extension, of eternal presence in the world and eternal being of the world as well. Cosmos is the supreme incarnation of infinity. His mystery, undiscoverness and beauty set the only possible coordinates of life and demonstrate proportionality and excellence of the "heavenly" organization. Therefore, cosmos is at the same time the supreme incarnation of order. The Universe, from a speculative and scientific perspective, appears as an "order in infinity." In addition, the ancient Greek cosmology construed the concept of kó $\sigma \mu \rho \varsigma$ as both an order and a beauty. At the same time, cosmos is a system that shows the unity of elements within the common matrix. If a Man is not an alien in the Universe we have to admit that all mentioned factors (infinity, order and unity) must have inevitably reflected in his earthly life and social practices. Megapolis appears as by far the best kind of the earthly way of life and life-space organisation due to the high level of its rationality and prevalence. Probably, in its "matrix" the will to order, the will to unity and the impulse to infinity are reflected as well. In our opinion, the impulse to infinity represents the quintessence of Homo Urbanus' intentions, namely — "transgression." Transgression here implies the desire to go beyond the limitations of time and space. This statement correlates with an idea of a vital "impulse" as the basis of human life, propounded by Max Scheller, the founder of the philosophical anthropology [Scheller, 1988: 43].

Defining the essence of the transgression, we will refer to the aphorism by Michel Foucault: "Transgression is an action which involves the limit" [Foucault, 1977: 33]. The transgression in the history of science is represented as a process of transcending of social norms, prohibitions and taboos. Some inquiries by Sigmund Freud and Jacques Lacan consider the desire and aversion as the driving forces of the processes of transgression [Freud, 2013]. The Friedrich Nietzsche's, idea of the "Overman" (the Übermensch) postulates the going beyond the limits of particular existence as well: "Man is something to be surpassed." ("Der Mensch ist Etwas, das berwunden werden soll!") [Nietzsche, 1990: 175]. This is quite correlating to Martin Heidegger's "eluding beyond ontic orders... beyond the boundaries of enslaving structures such as language, mentality, society" [Heidegger, 1993: 240]. Georges Bataille, interprets the transgression as "the supreme care of the first principles, the aspiration to overcome the boundaries of the finite in social experience... a man desires to turn away from the place of fleshly birth, to rebel internally against the fact of dying, do not trust the body at all, as well as all random and perishable within ourselves" [Bataille, 2006: 531]. Literally, a person rebels against the finality of earthly existence and seeks to infinity, to the eternity of the self-existence and the existence of the world. The ideas of existentialists could be considered in the same way. As an example, we can mention "The Rebel" by Albert Camus and his protest against "the meaninglessness of the incomprehensible and unjust fate of a Man" [Camus, 1990: 126]. Presently, the studies of transgression seem to be ambiguous. Can Altay defines transgression as a creative freedom that transcends the limits of society [Altay, 2013]. Gil Doron interprets the new Urban architecture as a transgressive way to confront the "dead zone" of the city [Doron, 200: 249]. Ursula Rao describes the transgression as innovative political intentions [Celebrating Transgression, 2006]. Mehdi Kacem interprets the transgression as the game, irony and catharsis. In the same time, it appears as a going beyond the ordinary experiences [Kacem, 2014].

However, despite a large amount of information, the megapolis was not practically considered in the anthropocosmic context until now. The concept of transgression did not appear as the unifying force of urban and cosmic processes as well. This article attempts to fill this gap by initiating a comprehension of the relationship between the declared phenomena. 


\section{Main Part of Research}

We define a transgression as an existential phenomenon of being. Its essence appears as the will of the Homo Urbanus to go beyond the limits of time and space, beyond the limits of ordinary experience and other frames of possible-impossible. This reveals the strong aspiration of Man for existential freedom, the establishment of the personal immortality which corresponds to the infinity of the Universe. Megapolis, in our opinion, embodies the mentioned intentions in many of its basic manifestations. Some of them are following:

a) a special organization of time and space,

b) priority of speed,

c) the fractal nature of the city,

d) planetary thinking of the city-dwellers.

It is important to realize that mentioned phenomena are naturally organized as an environment. The violation of this environment may cause unexpected results: probably the formation of new boundaries or even the destruction of the City environment.

Anthropic time. The city, as well as a Man, has its own history in time: it is born, develops and can die. It is no wonder that one of the most famous books by Jane Jacobs on urban studies is called "The Death and Life of Great American Cities." Each city has its unique temporhythm but megapolises' tempo-rhythm differs by its intensity. The sense of the city-time is always subjective because it is treated directly by the city-dweller, whose lifetime is "inserted" into the lifetime of the city. In this context, the concept of "anthropic time", proposed by a philosopher Volodymyr Khanzhy appears as the most appropriate. "Anthropic time" is a system that expresses human activity in terms of duration, order (an aspect of form) and semantic load (content aspect)" [Khanzhy, 2015: 262]. Authors admit the assertion of Elena Burlina that "in its light version an anthropic principle implies an understanding of time as an object correlated to a person, who occupies the position of an observer. In its strong version, time is considered as totally included into the person and, consequently, the "observer" becomes equal to the idea of the creator of time (the reason of time)." It is impossible to individualize the anthropic time as well as to make an exhaustive classification of city-dwellers. Nevertheless, it is necessary to identify some specific innovations of the megapolis that determine its temporality for the Homo Urbanus.

A megapolis dweller is the "creator of time" and at the same time the "user" of it, who dialectically combines light and strong anthropic-temporal principles. There are some examples. Due to the implementation of the artificial light and climate technologies, in many commercial locations, the customer finds himself in an environment of "eternal spring", where the illusion of being outside the change of time modes is created. The growing popularity of the shopping malls among the city-dwellers makes us believe that this tendency is nourished not only by the consumerism but also by "falling out" of the time, the transition from intensive tempo-rhythm to the atmosphere of "infinite time", beyond the ordinary traffic. The same effect of "timelessness" is achieved by the non-stop mode of many city service options that change the usual boundaries of night and day, beginning and end of the processes. Digital technologies, widely available to the megapolis dwellers, also allow "overcoming" the boundaries of the earth's time zones at any time of the day. The typical city-dwellers' time troubles (lack of time, time deficit) increase the deep necessity for unlimited temporality, freedom from the frames of time.

Let us have a look at the phenomenon of "selfie" mania among the gadgets users. The possibility to revive the pictures of the past at any time, to visualize plans and spontaneously record what is happening at the moment, lead to the fact that the permanent photo-videofixation of the moments of life rotates in the "infinity" of replication, producing the effect of 
the existential fusion of times. Being of "out of time" is even more obvious for Web users such as freelancers working for foreign partners or gamers and other people, pathologically obsessed by the Internet. Moreover, drug addiction and alcoholism widely spread in the big cities always targeted the "falling out of reality", the "loss of time." The widespread megapolis phenomenon of "job addiction", which is paradoxically similar to the drug addiction, causes a "falling out of time" as well.

Another marker of megapolises is the tendency to "slow motion" - "slowing down time" in the "third places" of the city (the "third place" means not at home and not at work) [Oldenburg, 2000]. In many large cities, more and more places for public and social meetings appear nowadays: cafes, anti-cafes, co-working, lodgers, lounges, libraries. Such places provide a communication opportunity for different people and purposes (business meetings or friends parties), giving them a chance to get rid of time frames of work and household duties. In some megapolises, the "cafe culture" has become an indispensable attribute of a city lifestyle, a part of city history and city brand (Paris, Rome, and Barcelona). Another evidence of the megapolises' "slow motion" trend is the widespread practice of yoga, meditation, relaxation and floating. Thereby, Homo Urbanus deliberately builds his relation to the time, leaving its dictate behind. The person of any era had a possibility to "fall out" of time by reading a book or doing arts, but the massive "overcoming" of time frames became possible only in the era of megapolises, the era of high technologies development. A conscious person is able to find a balance between destructive and constructive types of managing the time. Transgressively striving for freedom from time, he attempts to organize the chaos of temporality using a strong anthropic principle such as effective time-management.

Priority of speed. The social processes that take place in the cities always have their reflection in the culture. Mentioned reflection is illustrated by the widely known suite of George Sviridov named "Time, forward!" This suite was composed in the years of the first space flights. During the postwar epoch of high-technologies development, the urbanization increase takes place. The "priority of speed" phenomenon, that touched upon different life processes of the megapolises, was forming as well. The phenomenon of speed is closely connected with the paradox of anthropic time. The process of speed increasing seems to overcome the temporal and spatial frameworks. The Man becomes independent of these categories, due to the mobility achieved by technical innovations.

The increase of vehicles speed, acceleration of various services and even the service of fast dating(speed dating) are the markers of megapolises. Modern civilization seeks to reduce distances by making transportation public and planetary. Often, people perceive the speed scale using the analogy of the speed of light, counting new and new records. The Japanese train JR-Maglev MLX01-1 accelerates to 578.4 kilometres per hour. A specialized bicycle and additional equipment allow the bicyclist to accelerate to 223 kilometres per hour. The Thrust SSC reactive automobile, driven by British pilot Andy Green, reached the speed of 1227,985 kilometres per hour, what is beyond of the sound barrier [Samyy bystryy, 2015]. Elon Musk has already presented the "Hyperloop" vacuum train project, capable of accelerating four times faster than a high-speed train and twice as fast as an aeroplane. However, Paul Virilio, the author of the science of speed (dromology), points to the danger of obsession with the idea of speed. The scholar predicts the further person's mobility loss caused by extreme "body urbanization". He asserts that "large cities lose their cognitive and aesthetic potential when becoming only the focus of speed" [Virilio, 2006: 182]. In addition, it is necessary to consider the dependence of the number of traffic accidents on the fact of speeding on the roads. 
The will to speed manifests itself in other aspects of the city life. In the field of information, there is an obvious seek for faster processing of information and a reduction in the informational messages. Web communication and SMS show the reluctance of many interlocutors to write long and voluminous texts. Communication is simplified by using the fixed phrases, memes, abbreviations, slang or "emoji" that replace the long verbalization of feelings. "Fast and short" looks like a motto of gadget-communication. At the same time, as we already mentioned, emotional communication is realized in the real dimension of the "third places" of the megapolis. The safe balance of acceleration and deceleration also depends on the individual choice. Generally, the time continuum of a megapolis can be represented by the image of particular fractal; the figure 1 displays the phenomena of urban time in the life of Homo Urbanus: "falling out of time", slowing down, acceleration, transgression as a striving for temporal freedom and the time-management as the rationalization of temporal processes.

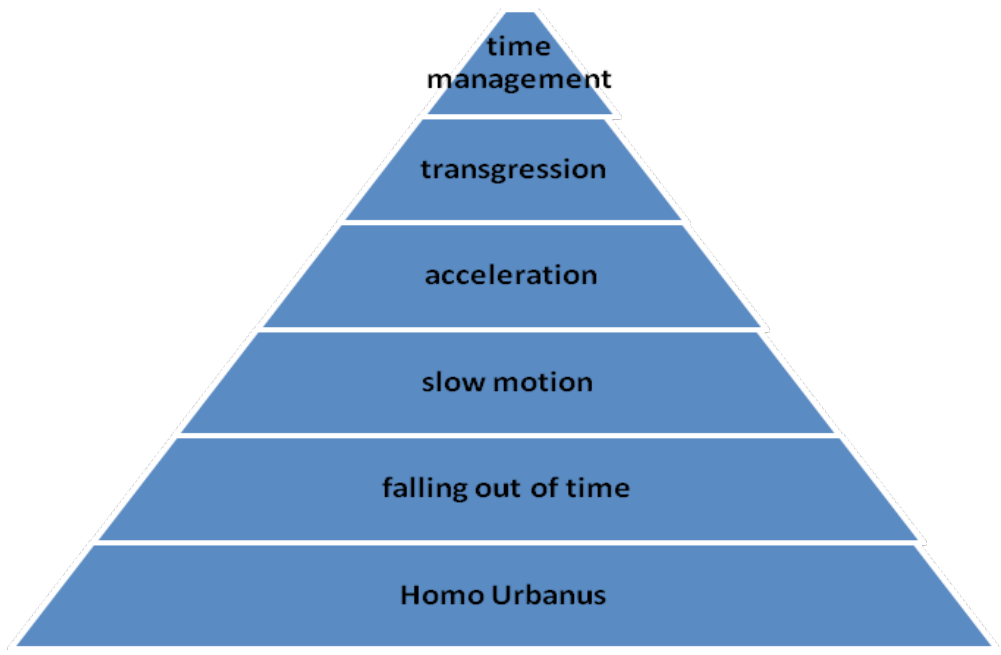

Fig.1. Time continuum of the megapolis

Anthropic space. The space of a large city gives a person numerous variants of the habitat and directions of internal migrations. From this point of view, it can be called "anthropic." We agree with Henri Lefebvre, who interpreted the megapolis lifestyle as an unceasing "production of space," "spatialization" (from the French "spatalisation", literally, the "space"), embodying "the right to a city" in anthropogenic circumstances [Lefebvre, 2002: 28]. Dorian Massey's idea about the unity of the autonomous and space movement is also interesting: "Setting on their ways in the city, people not just across the surface of the world fixed on a geographical map, but... they perceive their path in a world that is itself in continuous movement on the basis of unification of human and nonhuman strength" [Massey, 2000: 203]. Peter J. Riggs, defining the correlation between time and space, substantiated the fact of space expansion as an analogy of the flow of time [Riggs, 2017].

The architectonics of the megapolis, its visual representation in architectural artefacts (historically memorable objects that send to an immeasurable past, skyscrapers looking to the immeasurable future, and the present - the presence in the moment of synchronous coexistence of temporary layers) are an invariable attribute of "eternal movement" and "will to eternity". Urban semiotics and mythology have a tendency to date back the city 
chronology from ancient times if it is possible, despite the fact that each city has its own starting point in history. The metaphor of the "eternal city" (aeterna urbs), which is usually associated with Rome, Istanbul (Constantinople), Jerusalem, Kiev perfectly represents the mentioned intention.

The architectonics of the megapolis shows its three-dimensional spatial expansion: the city consistently grows upwards, to the sides and to the depth. The archetypal images of the city towers usually symbolize the transcendental vertical, the desire to "reach the heavens". At the same time, three-dimensional expansion demonstrates a transgressive act of total expansion in the space, aspiration to global infinity. Skyscrapers - an invariable attribute of megapolises, embody, on the one hand, the gigantic-mania of the architects, on the other hand, a pragmatic idea of space economy and composition of a "Smart home". Their "inhuman" heights cause some city-dwellers feel infernal. Sometimes they become a place where suicidal people take their own life. Unfortunately, the Empire State Building in New York (381 meters high, 115 floors), constructed in the midst of the Great Depression in the United States in 1931, became one of the most popular suicide locations. However, the "impudence" of earthly architects is growing every year. International Finance Centre in Hong Kong rises above the ground at 415 meters, Jin Mao Tower in Shanghai is 421 meters high, and Trump Tower in Chicago is 423 meters high Petronas Twin Towers in Malaysia are at 451.9 meters above the ground. "Burj Khalifa" tower's height is 828 meters, and planned in Saudi Arabia Jeddah Tower skyscraper will reach $1.1 \mathrm{~km}$ in height. Let us note the fact of eschatological motifs escalating in the art connected with skyscrapers. For example, the plots of Hollywood blockbusters, depicting the destruction of skyscrapers, (which unfortunately became real in 2001 in Manhattan) as well as, alien invasion plots, still wanders from one movie to another. The movies "Apocalypto", "Armageddon", "Melancholy", "2012", "The Day after Tomorrow" convey the existential tension in the consideration of skyscrapers as a symbolic limit, the absolute point of civilization, the arena of the struggle between the Good and Evil.

Megapolises are steadily growing in depth. The Underground City of Montreal is the largest underground "city within the city", extended for $20 \mathrm{~km}$. In different parts of the world, in Chicago, Dubai, Mexico City, in the Nevada desert, it is planned to build new "earthscrapers" hundreds of meters deep. The most suitable places for the underground cities construction are Canada, Sweden, Norway, South Africa and China. As the response to such intention, an "underground urbanistics", a new section of the city-science, took off in the early twentieth century.

The population of cities is growing at a rapid pace. There is a prediction that by 2025 the largest megapolises population will reach the point of 19-35 million people. Due to the megapolises population growth their area increases. Megalopolises, urban agglomerations and conurbations extend along the ocean shores. A quarter of The USA population is concentrated in the Northeast megalopolis (Bos-Wash corridor) that unites 40 highly populated agglomerations and covers more than 800 kilometres. Other large megalopolises are Tokaido (Tokyo-Osaka), Chippits (Chicago-Pittsburgh), San-San (San Diego-San Francisco). Pierre Merlin, making a distinction between spontaneous and regulated forms of cities growth asserts that "the metabolic (capable of expanding with indefinite forms) cities are about to become the mainstream. "The perfect city of the 21 st century is an open city that will never stop growing" [Merlin, 1975]. Highly relevant in this context is an Oswald Spengler's idea of a "world-city", which, as the main element of civilization, "will absorb the entire content of history" [Spengler, 2009: 164]. There is a paradox, that despite the steady 
growth of megapolises, they retain their identity in the perception of the city-dwellers and the tourists.

The architectural expansion of the metropolis is complemented by a sensory attack. In a big city, millions of irritants, influencing the senses, consistently influence a person. Movement in the crowd is full of tactile challenges. Visual challenges are delivered by storefronts, advertisements, transportation, landscape and architecture, weather phenomena and the most varied colours of this panorama. The olfactory organs are affected by the different smells of the city, and the taste organ is attacked by endless offers of meals. The acoustic of the big city is similarly varied. The sound of the rain, street conversations, obsessive music in public places, the rumbling of motorways and construction areas, which sometimes can exceed the pain threshold. The picture of such diversity can be supplemented by the phenomenon of spam - an abundance of unnecessary information, not initiated by the addressee. We mean that a sensory attack is a like a "cosmos" of diversity, striving for infinity. Enriching the human world with an infinite set of temptations, the city can cause one of the kinds of myxophobia - fear of redundancy. In fact, a person of the city requires a special sensory plasticity in order to adapt to such an environment. Many of inhabitants of megapolises have intuitively developed the original "sensory gating" that allows them to filtrate the incoming information and to catch in its flow only the necessary codes. It is obvious that both spatial expansion and sensory attack created by man require rational control to keep reasonable frames of processes.

The fractal nature of the city. Mise en abyme. Summarizing previous statements about anthropic time, priority of speed, anthropic space, with its three-dimensional expansion and sensory attack, reveals an idea of existence of some special mega-multi-structure of the city. It is obvious, that the structure reveals the endless construction, complication and fragmentation of its fragments. At the same time the fragments appear "inserted" into each other like a fractal, a Matryoshka doll or "mise en abyme" (literally French "falling into abyss"), the recursive art technology ("a dream in a dream", "a story in a story", "a picture in a picture", etc.). "In the city as in the meta-system, consisting of systems, which consist of subsystems of lower degree, hierarchically "nested" territories... networks, population density, and other demographic and sociological characteristics of urban culture appear as the fractals that vary in the degrees of complexity" [Nikolayeva, 2012]. Revising the urban empiric, we can find an obvious chain of fractals of the habitat of a city-dweller: apartment — house — district street - place of work - transport - places of consumption - location of leisure and communication. In each cluster, the Homo Urbanus plays particular social roles, which can also be "fractalized": from a family member to a corporation employee or a participant in citywide movements. You can consider any social organizations, groups, interpersonal relationship as fractals. The communication of citizens seems to be multifractal too, what is shown by numerous examples from auto-reflection to the dialogues and polylogues in the social groups. The ideas of Marilyn Hamilton, who uses for the description of the large city the metaphor of a hive (similar to the fractal), where everything is interconnected, and each "bee" participates in the general activity In the context of the analysis, appear relevant in the context of analysis of the fractal nature of a large city. As a result, the city appears as a living multi-level system in the continuum of time and space. We also venture to declare that the being of a Man is also naturally fractal. Such idea is increasingly justified by synergistic [Gowan, 2010]. Omitting the purely biological components of Man, it is possible to admit that the soul-spirit-body triad is "inserted" into the human personality and, forming its essence, flow one into another. Spiritual aspirations are nourished by mental impulses. 
Spiritual crises and weak-soul phenomenon on one hand lead to the bodily Psychosomatic manifestations, or, on the other hand, in the case of conscious lifestyles, develop healthy, harmonious existence. Except of the space of the Cosmos, the space of the Earth and the space of the city, each person has an infinite inner "space". It appears as "the source of the strength, as the place to get rid of something heavy and put some space aside for something more important." This is a statement of Bogdan Andreytsev who is an author of symbolic sculpture "Inner space", which, in our honest opinion, perfectly illustrates the fractal nature of a Man (Photo 1) [Siderskiy, 2017]. The phenomenon of a fractal is directly associated with the composition of the Universe, which, according to many scientists opinion, consists of an infinite number of nested fractal levels of matter. Benoit Mandelbrot, the author of the book "Fractal geometry of nature", considered fractals as the leading structures of universal order in chaos [Mandelbrot, 2001].

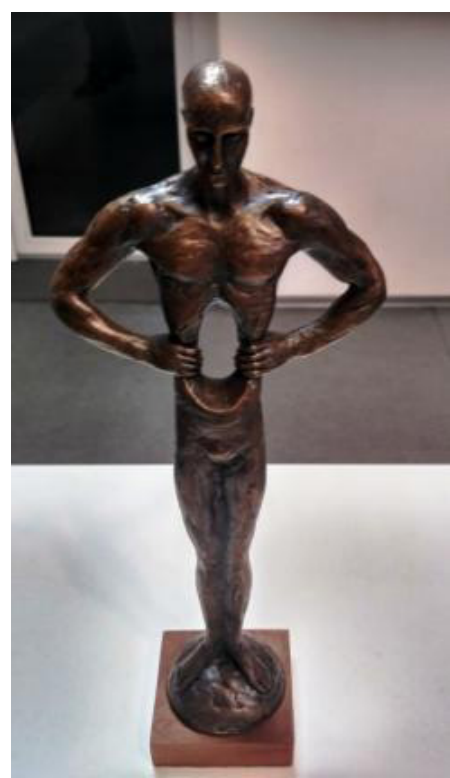

Photo 1. Innerspace Sculptor - Bogdan Andrejtsev

Anthropocosmic thinking. Developing an idea of the fractality of Man and city, it can be extrapolated on a planetary scale. Megapolises "inserted" in the general fractal of urbanization, globalization and virtualization of the world due to their contribution to the global processes. Peter Hall, comprehending cities interaction and their impact on the planet, uses such indicator for the classification of "global cities." Each megapolis is shown as an independent participant in a multi-level functional urbo-hierarchy [Hall, 1996].

Nowadays, in our opinion, many people develop a conscious attitude to the city and the world. Such attitude can be metaphorically called the "anthropocosmic thinking." We can outline two directions of anthropocosmic thinking: the mythological direction, which is associated with myths about the planetary threats and rational-realistic-thinking of Homo Urbanus who understands the relation of micro-macro processes and fills the responsibility for the planet. The ancient eschatological myths are being replaced in mass media by the ideas of a close "End of everything" such as "Parade of planets", "2012", "The planets Nibiru," 
Magnetic poles shift, destructive comets or asteroids. Despite the fact that some of these plots have a commercial basis and interest, we can say that the Cosmos still frights the mankind by its unpredictability and mysteries that does not exclude real dangers. The theories of the "Good Universe", which fulfils all the wishes if an application is "correct", appear as the antithesis to the previous. Neuro-Linguistic Programming models and the archetypal-fairytale image of the Higher Power paradoxically merge in modern pop-guides for a successful life, happiness and harmony. The modern man manifests an infantilism by the strong belief in miracles and welfare from above. At the same time, the power of the true believe is obvious and the good transformations are possible under its influence.

The researches on UFOs and contactee-people have been conducting for many years. Some messages from "supreme" alien races periodically appear on the Internet. At the same time, the mass media permanently inform the public about the dependence of the human health condition on the outer-space phenomena such as magnetic storms, solar flares, real climate change. The modern high technologies of everyday life, such as satellite antennas, satellite navigators allow us to observe the whole planet. Planet-wide Wi-Fi becomes the matter of the near future, (projects of Elon Mask), as well as the human expeditions to other planets. However, the highest manifestation of planetary thinking is reflected in the search for effective models of the human civilization development, conservation of nature and the further discovery of the outer space.

The planetary thinking manifests itself through the intellectual Internet platforms designed to consolidate the creative class of cities. The positive urban prospects are postulated in the pages of the "Asian multimedia utopia", founded by the informational agglomeration of megapolises (Hong Kong, Singapore, Shanghai), in the Internet project "Urban Multimedia Utopia" started by the international architectural school "Bauhaus Dessau, where the project of "highly-rational-city" as... a hyper-powerful matrix of interconnected forms is presented" [Chepelik, 2003]. Such projects contribute to the dissemination of the ideas of an integral and creative city, comfortable for a person's life and environmentally friendly.

A reasonable approach in the context of anthropocosmic responsibility for the city and the fate of the planet is reflected in dozens of modern books with similar key names — "Homo Urbanus." Stanislav Lose optimistically interprets the future city dweller as "the inevitably universally creative." Jelle Roymer explores the hypotheses of urban development in the context of the general evolution theory. Elisabeth Oberzaucher analyzes the behavioural reactions of large city dwellers. Thierry Paco shows the continuity of urbanization and morality. Maryna Prepotenska analyzes the existential modes of a megapolis dweller. The development of megapolises is increasingly reflected in the virtual mega-dimension. The adherents of the synergetic theory of the Universe argue that the worldwide informational web is already forming in an innovative structure of Synergonet - "the collective intellect of humanity that entered the epoch of the noosphere." The authors agree with an assertion of the "fractal nature of the entire network infrastructure as a super-complex self-organizing transportation and information system. Its main characteristics are openness, non-linearity and coherence." All these facts testify to the development of man's anthropocosmic thinking both in the scope of the audience and in the scale of the planetary problems included into the cosmic projection.

\section{Conclusion}

After examination of the megapolis phenomenon in the anthropocosmic context, we became insured that the topic of the city has long been inscribed in the overall perspective of cosmism. The human environment was organized and functioned in the natural, cosmic 
and sacred canons. The anthropological turn in the science of the second half of the $20^{\text {th }}$ century, coinciding with the active phase of urbanization and the growth of megapolises, was characterized by the justification of the theory of anthropocosmism.

We outlined the main existential moduses in the context of anthropocosmic thinking of "Homo Urbanus" which are the will to infinity in the overcoming of space-time limits (transgression), ability to organize the continuums and the aspiration to the planetary unity. We defined the relevant attributes of a modern urban lifestyle as a substantial manifestations of transgression in the sense-of-life intentions and social practices of the city dweller (anthropic time, anthropic space, fractal nature of the city, anthropocosmic, planetary thinking of "Homo Urbanus.") The creative city dweller, who has a will to infinity, seeks not to "conquer", but to "save" the nature, conserve all living creatures and justify the cosmic prospects for the mankind development.

As a result, the future of megapolises and the civilization depends on the free transformational activity of people. We were convinced that the will to infinity is followed by the desire for awareness and orderliness. The more conscious Homo Urbanus is, the more effectively he is able to act in the environment of megapolis challenges to prevent chaos and destructive behaviour. This requires the high intelligence and developed spirituality for people who are able to impact the future. The synergetic processes, corresponding to the synergy of the space of the Universe, could also be seen in the development of the urban environment. This field, in our opinion, requires a separate study.

\section{References}

Altay, Can. Transgression in and of the City. The Architecture of Transgression. Volume 83, Issue 6, 2013. https://doi.org/10.1002/ad.1682

Augustine of Hippo. O Grade Bozhiem. Minsk: Kharvest, 2000. -1296 s.

Bataille, Georges. Granitsy poleznogo. Moskva: Ladomir, 2006. — 742 s.

Camus, Albert. Buntuyushchiy chelovek. Filosofiya. Policies Art. Moskva: Politizdat, 1990. - $415 \mathrm{~s}$.

Celebrating Transgression. As Method and Politics in the Anthropological Study of Culture. Edited by Ursula Rao and John Hutnyk. Oxford: Berghahn, 2006.

Chepelik, Oksana. Utopicheskie aspekty sovremennogo urbanizma. Moskow art magazine. 51/52, 2003. http://xz.gif.ru/numbers/51-52/urbanizm/

Doron, Gil.The Dead Zone and the Architecture of Transgression. Journal City. Volume 4, Issue 2, 2000: 247-263.

Foucault, Michel. A Preface to Transgression. Language, counter-memory, practice: selected essays and interviews by Michel Foucault. 1977. P. 29-52.

Freud, Sigmund. Totem i tabu. Psikhologiya pervobytnoy kultury i religii. SPb.: Azbuka, 2013. - $256 \mathrm{~s}$.

Germes Trismegist i germeticheskaya traditsiya Vostoka i Zapada. Kyiv: Iris, 1998 - $623 \mathrm{~s}$.

Gowan, John. Nature's Fractal Pattern, 2010. http://www.johnagowan.org/info.html

Hall, Robert. The World Cities. Heinemann, 1996.

Heidegger, Martin. Bytie i vremya. Moskva: Ad Marginem, 1993. — $451 \mathrm{~s}$.

Kacem, Mehdi Belhaj. Transgression and the Inexistent: A Philosophical Vocabulary. Bloomsbury Academic, 2014.

Kirilenko, Galina and Eugene Shevtsov. Kratkiy filosofskiy slovar. Moscow. 2010.

Khanzhy, Volodymyr. Metodologicheskaya rekonstruktsiya antropologicheskoy paradigmy vremeni: kontseptsiya antropnogo vremeni i chelovecheskoy istorii. Filosofiya osviti. 
№ 2 (17), 2015: 260-270.

Kholodny, Nikolay. Izbrannye trudy. Kiev: Naukova dumka, 1982. — $443 \mathrm{~s}$.

Lefebvre, Henri. Proizvodstvo prostranstva. Sotsiologicheskoe obzrenie. T. 2, No. 3, 2002: 27-29.

Mandelbrot, Benoit. Fraktalnaya geometriya prirody. Mn.: Knizhnyy Dom, 2001. — 655 s.

Massey, Dave. Traveling thoughts. Honor of Stuart Hall. Eds. P. Gilroy, A. McRobbie. Verso, 2000: 225-232.

Merlin, Pierre. Novye goroda. Moskva: Progress, 1975. - $254 \mathrm{~s}$.

Nietzsche, Friedrich. Po tu storonu dobra i zla. V 2 tt. T 2 Leningrad: Sirin, 1990: 149-325.

Nikolaeva, Elena. Goroda kak fraktalnye perekrestki mira. Labirint. 3, 2012: 92-106.

Oldenburg, Ray. Celebrating the Third Place: Inspiring Stories about the "Great Good Places" at the Heart of Our Communities. New York: Marlowe \& Company, 2000.

Riggs, Peter J. Is There a Spatial Analogue of the Passage of Time? Philosophy and Cosmology. Volume 18, 2017: 12-21.

Samyy bystryy transport na Zemle, 18 aprelya 2015. https://meduza.io/shapito/2015/04/18/ samyy-bystryy-transport-na-zemle

Scheler, Max. Polozhenie cheloveka v Kosmose. Problemy cheloveka v zapadnoy filosofii. Moskva, 1988: 35-94.

Siderskiy, AndrIy. MoYi kartini — zbroya, yaka vplivaE na psihIku. Gazeta.ua, 22 sIchnya 2017 https://gazeta.ua/articles/culture/_myi-kartini-zbroya-yaka-vplivaye-napsihiku-hudozhnik-andrij-siderskij/747708?mobile=false

Spengler, Oswald. Zakat Yevropy. Obraz and deystvitelnost. Moskva: Popurri, 2009. — T. 2. $-704 \mathrm{~s}$

Toffin, Gerard. La notion de ville dans une societe asiatiquc traditionnellc: l'exemple des Newar de la vailee de Kathmandou. L'homme. T. 22, No. 4, 1982: 101-111.

Tsiolkovsky, Konstantin. Filosofiya kosmicheskoy epokhi. Moskva: Akademicheskiy Proekt, 2013. - $239 \mathrm{~s}$.

Vernadskiy, Vladimir. Nauchnaya mysl kak planetaarnoe yavlenie. Moskva: Nauka, 1991. — $271 \mathrm{s.}$

Virilio, Paul. Speed and Politics. New York: Semiotext(e); 2nd edition, 2006.

Voytsehovich, Vyacheslav. Anthropic principle as the integrating nucleus of post-nonclassical science. Philosophy and cosmology. 2010: 33-37. 